\title{
O óbvio da informação científica: acesso e uso'
}

\section{The obvious on scientific information: access and use}

Maria das Graças TARGINO2

\section{RES U MO}

O texto aborda o acesso e o uso da informação científica, a partir da sua concepção e função para o avanço científico e tecnológico dos países. Na sociedade contemporânea, as redes eletrônicas de comunicação (ênfase para a Internet) agilizam o fluxo informacional, ao tempo que exigem mais rigor para a seleção da informação científica consistente. Entre alternativas de acesso à informação, além dos periódicos científicos (impressos ou eletrônicos), está o movimento de acesso livre à informação científica, que recorre a repositórios de acesso livre e/ou a softwares de código aberto. Há outras opções: (1) o Creative Commons, projeto sem fins lucrativos, que disponibiliza licenças flexíveis para obras intelectuais, incluindo textos científicos e o (2) Open Source Journalism (OSJ), que incentiva a participação efetiva da comunidade na produção de notícias. Em qualquer caso, reiterase que inexistem soluções únicas para sociedades múltiplas. Isto é, cada inovação tecnológica tem o seu próprio espaço e o seu próprio público (sem riscos de o mundo tornar-se uma aldeia global), de modo que o acesso e o uso à informação científica ocorrem, também, de forma multifacetada.

Palavras-chave: informação científica; Internet; acesso livre; Creative Commons; Open Source Journalism.

\section{A B S T R A C T}

This work approaches the access and use of scientific information, based on its conception and role aimed at the scientific and technological advances of the countries. In contemporary society, communication electronic nets (with emphasis on the Internet) speed up the informational flow, but, at the same time, require greater rigor in order to select consistent scientific information. Among the information access alternatives, besides scientific journals (printed or electronic), there is the free information access movement, which resorts to free access databases and/or free code software. There are other options, such as (1) the Creative Commons, a non-profit project, that makes flexible licenses available to intellectual productions, including scientific texts; and (2) the open source journalism (OSJ), which encourages an effective community participation in the news production. In any case, there are no single solutions for multiple societies - which means to say that every technological innovation has its own space and its own public, in such a way that the access and use of scientific information occur, also, in many differently faceted forms (and therefore, the world moves on without risks of becoming a global village)

Keywords: Scientific information; Internet; free access; Creative Commons; Open Source Journalism.

\section{NTRODU ÇÃ O}

Em outubro de 2002, durante o XII Seminário Nacional de Bibliotecas Universitárias, ocorrido em
Recife, Pernambuco, na condição de participante da mesa redonda Contribuições da tecnologia para o desenvolvimento da produção científica e da publicação eletrônica, enfocamos a vinculação entre as novas

\footnotetext{
1 Fundamentado em palestra proferida durante o XIV Seminário Nacional de Bibliotecas Universitárias, out. 2006, Salvador, BA, Brasil. 2 Jornalista e Professora Doutora em Ciência da Informação. Professora, Departamento de Comunicação Social, Universidade Federal do Piauí. SG 4, Campus Ininga, 64050-900, PI, Brasil. E-mail: <gracatargino@hotmail.com>.

Recebido em 31/10/2006 e aceito para publicação em 26/4/2007.
} 
tecnologias e o incremento da produção científica, levantando, à época, um questionamento central: há, de fato, relação de causa e efeito entre tal incremento e a expansão das redes eletrônicas de informação e de comunicação, com ênfase para a Internet, ou se trata de mera ilusão ou mera retórica?

O tema que hoje, nos foi delegado - informação científica: acesso e uso - possui similaridade com o anterior, na medida que requer, antes de tudo, a necessidade de conceituação da informação científica. Se a formação e a emissão de conceitos constituem por si mesmos processo complexo e dinâmico, há um ponto consensual e unívoco, ou seja, em qualquer circunstância, a expressão informação científica é vista por pessoas, as mais distintas, de maneira absolutamente idêntica, sob uma só forma de interpretação, fundamentada até mesmo nos dicionários mais genéricos: informação científica como a informação relativa à ciência ou às ciências; informação científica como a informação que possui o rigor da ciência.

No que se refere à ciência, a compreensão da informação científica conduz à relevância da ciência como processo social, dinâmico, contínuo e cumulativo, que busca, essencialmente, desvendar e compreender a natureza e os seus fenômenos, por meio de métodos sistemáticos e seguros. No entanto, por conta da dinamicidade intrínseca à própria natureza, os resultados são sempre provisórios. Isto é, os seus sistemas explicativos não são permanentes. Inserem-se num processo ininterrupto de investigação, criando e alterando convicções, modificando hábitos, gerando leis, provocando acontecimentos, ampliando, de forma permanente e progressiva, as fronteiras do conhecimento - o que permite inferir, mesmo sem pretensões históricas, que a ciência influencia a humanidade e é por ela influenciada, o tempo todo.

Ciência e tecnologia (C\&T) caminham pari passu com a história da humanidade. Há sintonia entre o continuum histórico das civilizações e a mentalidade sociocultural e científica. C\&T nunca são neutras, porquanto estão sob a custódia de seres humanos. Seres humanos possuem escalas de valores, crenças e interesses, individuais e coletivos. Agem em função de ideais econômicos, políticos, sociais e culturais, de modo que a tecnologia acaba, sempre, a serviço de países, instituições e grupos, aos quais compete a sua produção, o seu controle, a sua transferência e o seu uso.
Em outras palavras, homens possuem ideologias. Aqueles que fazem ciência, como todos os demais seres humanos, não conseguem se despir das suas escalas de valores, quando do exercício da profissão. Isto é pensar em neutralidade da ciência, perspectiva irreversivelmente ultrapassada. Quando muito, o que se consegue é a objetivação, como tentativa de reproduzir a realidade sem disfarces via postura crítica e racional. Objetivação, no sentido de perceber o conhecimento como reconstrução, como inserção que o pesquisador faz no seu objeto de estudo via teorização e técnicas que o permitem recortar e esculpir. Não se trata de neutralidade, mas da percepção da convivência inevitável da ciência com a ideologia, desde o momento que se concebe o conhecimento científico como a produção de indivíduos que carregam consigo carga ideológica. Esta convivência não significa favorecimento ou dissimulação, mas redução ou desmascaramento da ideologia.

\section{NFORMAÇÃ O \\ CIENTÍFICA - RELEVÂNCIA E CONTEXTUALIZAÇÃ O}

A relevância da ciência para a humanidade corresponde ao reconhecimento da informação científica como mola propulsora das mudanças que afetam a sociedade contemporânea. Temos uma sociedade, cujo eixo central é a globalização. Globalização, por sua vez, como processo, que pressupõe, sempre, acesso às novas tecnologias de informação e de comunicação, as quais favorecem of fluxo informacional.

Assim, em pleno século XXI, a cultura do pós-modernismo impera no meio social, e o eixo da economia passa a ser a produção, a distribuição e a difusão da informação. A informação, mais do que antes, se impõe como o motor da História. Os conflitos e as lutas da sociedade atual passam a se desenvolver nesse circuito, consolidando a decantada divisão - países ricos em informação e países pobres em informação.

Tal como a globalização, que ora concorre para uma civilização transnacional com acesso igualitário a aplicações tecnológicas e a informações em todos os níveis, ora age como instrumento de desemprego e de miséria, além de elemento esfacelador das fronteiras nacionais e da soberania nacional, a informação também é ambivalente. Isto é, fortalece a democracia, 
ao favorecer o exercício da cidadania, o qual pressupõe acesso à informação para o cumprimento de deveres e a reivindicação de direitos. Em contraposição, como Targino (2006) chama a atenção, figura como fator neocolonizador, quando conduz a formas de dominação econômica, política e cultural, provocando a deculturação.

Como decorrência dessa valorização da informação, num processo irreversível, o desenrolar das atividades humanas, em todas as instâncias, depende, cada vez mais, da gestão técnica e científica. A simples união dos cientistas em torno de objetivos comuns não garante o desempenho da atividade científica. Este requer a formulação de políticas públicas abrangentes, definidas pelo Governo em consonância com os setores da sociedade civil, com destaque para a iniciativa privada, e que variam segundo o estágio desenvolvimentista das nações e regiões.

Os países do Terceiro Mundo, por exemplo, investem em C\&T, bem menos do que os centrais, priorizando a pesquisa aplicada. Conforme o próprio Ministério da Ciência e Tecnologia, MCT (Brasil, 2006a), a área de C\&T, de acordo com parâmetros internacionais, incorpora as ações de pesquisa e desenvolvimento experimental (P\&D) e as atividades científicas e técnicas correlatas (ACTC). Mas os recursos aplicados pelo Governo Federal e pelas empresas, além dos valores constantes dos indicadores consolidados e das comparações internacionais, referem-se apenas ao binômio P\&D, vez que as discussões acerca dos procedimentos metodológicos concernentes aos investimentos em ACTC, ainda estão em andamento.

Independente dessas observações, o fato é que, enquanto as nações avançadas destinam cerca de $3 \%$ do seu produto interno bruto para a consecução de atividades científicas e tecnológicas, o Brasil, décima segunda economia do mundo (depois de ter ocupado a oitava posição, em 1998), ocupa o $30^{\circ}$ lugar no ranking científico mundial, com investimento de tão-somente 1,37\% do seu PIB em C\&T, conforme dados recentes (Brasil, 2006b).

Dizendo de outra forma, diante da escassez de recursos, pesquisadores e cientistas brasileiros carecem de condições mínimas para a sua atuação. Entre elas, facilidade de acesso à informação, infra-estrutura adequada, condições favoráveis ao intercâmbio de informações e de experiências com os demais especialistas, e também, meios para a divulgação das pesquisas empreendidas, de forma ampla e irrestrita, haja vista que, conforme temos enfatizado, com veemência, a divulgação de resultados é etapa, e não complemento, das investigações de teor científico, configurando-se como a expressão mais elevada da função social do pesquisador.

E é exatamente essa circulação de resultados, ou melhor, o fluxo informacional intenso que configura o processo de comunicação científica, processo este, que propicia a soma dos esforços individuais dos membros da comunidade científica, por meio da troca de informações, configurando ciclo inesgotável de recepção e transmissão de dados. É a ciência comunicada no seu próprio âmbito, ou seja, é a ciência filtrada dentro de sua própria estrutura. Constitui um sistema global que incorpora todas as medidas, facilidades, ocasiões, publicações, recursos e diretrizes que determinam como as mensagens científicas são transmitidas, o que pressupõe dinamismo interno que se propaga por todo o seu universo.

Na verdade, a comunicação científica fundamenta-se na informação científica (Figura 1). Esta gera o conhecimento científico. Este representa um acréscimo ao entendimento universal até então existente sobre algum fato ou fenômeno. Isto porque a ciência possui caráter evolutivo e mutável, o que faz da pesquisa científica seu instrumento-mor e da comunicação científica seu elemento básico. A informação é, em última instância, o insumo básico da comunicação científica. Cada pesquisador é, ao mesmo tempo, produtor e consumidor de informação. Só a comunicação científica permite somar esforços, intercambiar experiências, evitar duplicação de tarefas. O pesquisador, sistematicamente, permuta informação com seus pares. Como um computador, recebe (input), processa/apreende (processing) e repassa informações (output), consolidando um ciclo contínuo de recepção e transmissão de dados.

É esse ciclo que, efetivamente, dá conta do acesso e do uso da informação científica. Então, é necessário precisar a força das inovações tecnológicas como recursos que facilitam o acesso e o uso da informação. Mas, ao contrário do que muitos apregoam, a explosão bibliográfica ou explosão informacional não acontece a partir da Internet. Inicia ainda no século XV, graças ao advento da escrita e da imprensa, que acarreta a laicização e a popularização dos conhecimentos, alcançando o seu ápice no século XX, devido a múltiplos fatores intervenientes. De forma sucinta: 


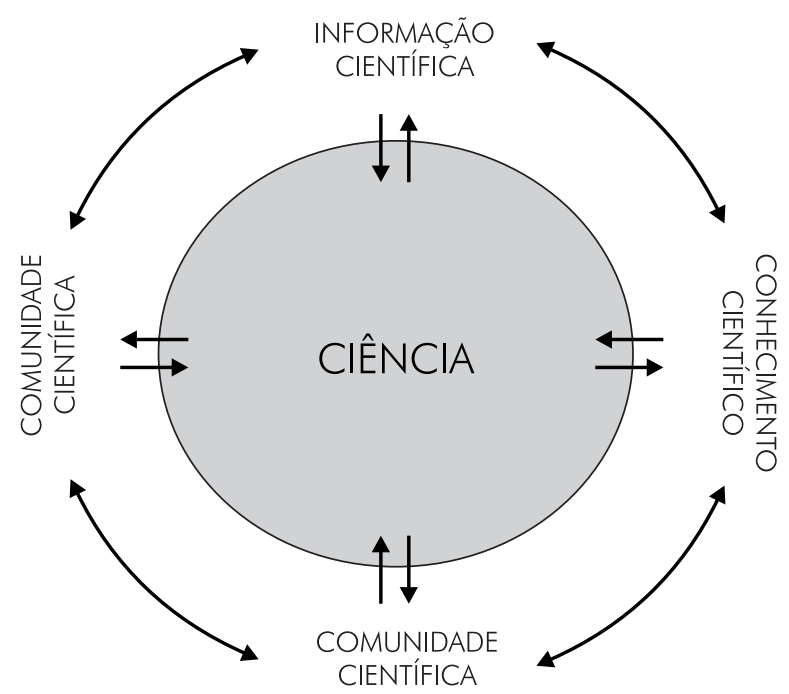

Figura 1. Representação simplificada do processo de comunicação científica.

avanço da C\&T; incremento da investigação científica; aperfeiçoamento do processo de defesa nacional; exploração espacial; industrialização crescente; número elevado de pesquisadores; especialização mais e mais acentuada; possibilidade de impressão rápida; produtividade média por pesquisador estimada pelas agências de fomento à pesquisa em quatro artigos por ano; $\mathrm{e}$, por fim, o impulso das novas tecnologias, com ênfase para a Rede.

Sob esta perspectiva, o aumento exponencial de registros informacionais provoca, tanto reflexão acerca da distinção entre dados e informação, como a necessidade imperiosa de agregar informações sob uma visão sistêmica, a fim de facilitar o acesso. Quanto ao primeiro item, há nítida diferença entre os termos, com o adendo de que, informação para alguém, pode ser simples dado para outrem e vice-versa, face às particularidades intrínsecas aos nossos repertórios cognitivos. Os dados são tão-somente a matéria prima da informação, despojados de valor intrínseco. Dados brutos podem ser informação, mas não necessariamente. Para que isto se dê, devem ser imbuídos de forma e de significado. Datas de nascimento ou a escolaridade dos indivíduos são meros dados. Se devidamente explorados para comportar significados são transmutados em informação. Exemplificando: num estudo acerca do acesso ao ensino fundamental numa determinada comunidade da zona rural, a data de nascimento e a escolaridade conduzem à compreensão mais ampla do analfabetismo ou da escolarização.

Quanto à informação, constitui matéria-prima do conhecimento. Só é conhecimento a parcela dos elementos que se incorporam ao repertório cognitivo e conceitual do ser humano. Dentre o manancial de informações às quais o ser humano tem acesso cotidianamente, só o que consegue reter, apreender e compreender é conhecimento. Resumindo: a informação é capaz de produzir conhecimento ou não, da mesma forma que ocorre com o dado em relação à informação. Esta pode atuar como formadora de estoque ou como agente modificador, capaz de gerar novos conhecimentos. No primeiro caso, tem-se a função estática da informação: estoques per se não são responsáveis pela concepção de conhecimentos e nem transmutam a realidade. Somente uma ação que se posicione como agente modificador confirma a produção do conhecimento.

Ao tripé - dados, informação, conhecimento -, ajunta-se novo elemento, a sabedoria, dentro da denominada "hierarquia quádrupla" de Mason (1990). Sabedoria na acepção de habilidade para gerenciar informações e conhecimentos, selecionando os mais relevantes em situações distintas, em meio ao processo de tomada de decisão. Trata-se do elemento mais importante para docentes, pesquisadores e cientistas, uma vez que se refere ao modo de operacionalização das informações e conhecimentos assimilados, exercendo papel de destaque no processo de comunicação articulado pela comunidade científica.

Quanto ao segundo elemento, qual seja, agregar informações sob uma visão sistêmica, mesmo sem detalhar a Teoria Geral dos Sistemas, interessa pensar sistema como um todo complexo e organizado, cujas partes intrinsecamente relacionadas perfazem dinamicidade sistemática e contínua, e cuja articulação visa a um fim comum. Falamos dos sistemas de informação em campos específicos, a exemplo dos sistemas de informação em saúde ou em agronomia.

Graças à força crescente da informação como fator de transmutações sociais e à concepção do sistema como princípio organizador do conhecimento, o significado da informação nos sistemas adota função estratégica. Isto significa que a informação nas organizações concilia metas e objetivos com formatos e conteúdos diversificados das diversificadas fontes de 
informação, estruturadas ou não, em sistemas disponibilizados no ambiente organizacional. As organizações são unidades sociais ou agrupamentos humanos, (re)construídos intencionalmente, com o fim de atingir metas previamente definidas.

\section{NFORMAÇÃ O \\ CIENTÍFICA - ACESSO E USOFACILITADOS?}

Por outro lado, retomando o acesso e o uso à informação científica, reiteramos a idéia de que, ao tempo em que a Internet, como representante-chave das novas tecnologias, favorece o fluxo informacional, não assegura, de forma alguma, a qualidade das informações disponibilizadas. O crescimento veloz da Rede e a sua presença nos cinco continentes são incontestáveis.

Registra-se a primazia dos Estados Unidos da América do Norte (EUA), (106,3 milhões), seguidos do Japão, enquanto o Brasil está no décimo lugar (geral), com 9,8 milhões $(5,7 \%$ da população brasileira), ocupando o segundo lugar na América Latina, em termos de proporção da população com acesso à Internet, perdendo somente para o Uruguai que atinge $9 \%$ da população. Ao lado da quantidade de usuários, há verdadeira avalanche de informações nas quase três bilhões de páginas disponíveis na Rede, em seus 71 milhões e 300 mil sites, aproximadamente (Internet..., 2001).

Porém, todos esses números, nem são sinônimos de produção científica crescente, nem de acesso ou uso crescente. Isto porque, diante de tantos e tantos dados, há um novo mal característico deste século - a ansiedade de informação. Profissionais das mais diferentes áreas se sentem atormentados por não conseguirem reter todas as novidades geradas em seu campo de atuação ou dominar informações que aparecem nas rodas sociais, tais como: os ganhadores do Prêmio Nobel, nas diferentes categorias; o Oscar, nas diferentes modalidades; as oscilações no mundo econômico; os best sellers do momento; os cantores da moda; as mudanças políticas dos países vizinhos.

O esperado, em termos sociais, é que sejamos atualizados, produtivos, e, portanto, bem informados. Quem não corre em busca da informação, se situado no meio acadêmico ou científico, não sobrevive ou corre o risco de ser considerado como "animal estranho". E é óbvio: se isto toma dimensão gigantesca: podemos adoecer de ansiedade. Mal chegamos em casa, ligamos a televisão. Estamos atentos 24 horas em busca de novas informações sobre o mundo que nos cerca. Então, corremos o risco de não suportarmos o silêncio, e, assim sendo, perdemos a oportunidade de escutar o barulho do vento, o gorjeio dos pássaros, a música que paira no silêncio total.

Retomando o tema, indagamos: como discernir o científico do não científico? Como discernir o técnicocientífico do não técnico-científico? Como separar o joio do trigo? Como separar o "lixão" cibernético das informações consistentes? Com esta provocação, ressaltamos que as aplicações tecnológicas no processo de comunicação acarretaram, sempre, novas formas de relações sociais e práticas culturais, a começar pela escrita, que propiciou a consolidação da literatura e da imprensa, como antes dito. Não é, porém, relação simplista de causa e efeito, em que às alterações infraestruturais correspondem mudanças superestruturais ou vice-versa. A Internet ou o número maior de publicações eletrônicas não é sinônimo de produção científica, no sentido estrito do termo. Isto exige do internauta, cientista ou não, uma série de cuidados, no sentido de identificar, com mais rigor, o nível de fidedignidade dos muitos sites, o que requer capacidade de discernimento e bom senso, mas também, domínio de técnicas de busca no espaço virtual.

Se a Internet dá à comunidade acadêmica e científica a chance de se informar com mais agilidade, pode também gerar desinformação, caso os indivíduos não atentem para a importância da triagem das fontes eletrônicas. E, ao contrário dos primeiros temores fantasiosos, que davam conta do desaparecimento da biblioteconomia, mais do que antes, o bibliotecário ou, de forma mais ampla, o profissional de informação, solidifica o seu papel social. Persiste como essencial na organização da informação, na definição do fluxo de navegação de um site, na hierarquização das informações na web e assim por diante. Se tal atividade requer nova formação ou atualização profissional, na sua essência, essas são ações similares às que qualquer bibliotecário faz, ou deveria fazer, nas bibliotecas agora ditas tradicionais, visando, sempre, a facilitar o fluxo informacional.

\section{MOVIMENTO DE ACESSO LIVRE À I NFORMAÇÃO CIENTÍFICA}

Neste sentido é que ganham força iniciativas como a de acesso livre à informação científica, movi- 
mento que tem conquistado espaço, em nível de Brasil, por conta da iniciativa do Instituto Brasileiro de Informação em Ciência e Tecnologia - IBICT, (Instituto Brasileiro..., 2005), órgão do MCT e líder do Manifesto Brasileiro. $\bigcirc$ movimento mundial pelo acesso livre à informação, envolve quatro segmentos essenciais à produção e à disseminação da informação científica, quais sejam, a própria comunidade científica, as instituições acadêmicas, as agências de financiamento e/ou fomento e as editoras (comerciais ou universitárias). movimento surgiu em razão das dificuldades de acesso encontradas pela comunidade científica no modelo tradicional de publicação. Modelo este, fundamentado nas revistas científicas impressas, cuja aquisição, preparação técnica, armazenagem e recuperação das informações científicas, correspondem a custos elevados.

E, de fato, até mesmo no caso das revistas eletrônicas, persistem duas opções: acesso restrito e acesso aberto. Segundo Márdero Arellano; Ferreira; Carregnato, (2005), as revistas de acesso restrito prevalecem como modelo de publicação científica, mantendo proximidade com a versão impressa, até mesmo quanto ao sistema avaliativo. $\bigcirc$ acesso a seu conteúdo é pago, tanto por meio de assinaturas individuais, como de licenças de acesso a opções distintas de pacotes, providos por distribuidores e/ou editores especializados. No caso das licenças em pacotes, pode ocorrer (e ocorre), que as entidades assumam o pagamento de títulos não selecionados. No Brasil, por conta da iniciativa do Portal Capes (Coordenação de Aperfeiçoamento de Pessoal de Nível Superior), raras são as bibliotecas que assinam esses contratos.

As revistas de acesso aberto não significam necessariamente gratuidade. Se o movimento de acesso livre à informação científica recorre a repositórios de acesso livre e/ou a softwares de código aberto, a Open Archives Initiative ou Iniciativa dos Arquivos Abertos (OAI) representa, na sua essência, revisão do processo de comunicação científica, com base na implementação de soluções tecnológicas integradas. Apóia-se em ferramentas e procedimentos fundamentais: auto-arquivamento pelos autores; metadados padronizados para descrição; acesso livre à produção científica e o Protocolo OAI.

Ademais, o movimento do acesso aberto (Open Access) apóia o modelo de publicação pago pelo próprio autor, e também o modelo de auto-arquivamento de e-prints via protocolo de arquivos abertos. A priori, acesso aberto significa a disponibilização livre na Internet de literatura de caráter acadêmico ou científico, permitindo a qualquer um o uso de textos integrais dos documentos. É o resultado do acordo denominado de Budapest Open Access Initiative. Esta declaração realça as iniciativas dos arquivos abertos e do acesso aberto como recurso para incrementar o avanço científico e tecnológico mundial, mediante a disseminação irrestrita de artigos científicos dos distintos campos do saber, resistindo às pressões da indústria editorial e dos órgãos públicos que mantêm acervos valiosos para pesquisas.

As revistas eletrônicas de livre acesso comportam duas modalidades: as revistas gratuitas para o leitor e autor; as revistas gratuitas para os leitores, mas pagas pelos autores. As primeiras, em geral, são iniciativas não comerciais bastante simples, envolvendo instituições acadêmicas ou sociedades científicas e profissionais. No segundo caso, os custos são pagos pelos autores ou por suas instituições, o que assegura o acesso ao público e um padrão elevado de qualidade. Mas, como somente os artigos aceitos são pagos, as grandes revistas, que, com freqüência, recebem um número de submissões superior ao de aceites, enfrentam custo de processamento elevado. Conseqüentemente, os artigos saem a um preço elevado, sobretudo, para os pesquisadores das nações periféricas.

A este respeito, o The United Kingdom Parliament (2004) exemplifica, calculando que, se a Nature (cujo índice de rejeição chega a 90\%) adotasse tal modelo, o seu custo de edição oscilaria entre 10 a 15 mil dólares, por cada texto. Talvez, a solução seja a cobrança dos ma-nuscritos submetidos, quer aceitos, quer rejeitados. De qualquer forma, trata-se de opção ainda não consolidada, pois exige, até mesmo culturalmente, que assimilemos o hábito de pagar por nossos escritos. Assim, o mais adequado à realidade nacional é que as instituições de pesquisa ou ensino às que os autores estão vinculados, assumam o respectivo pagamento ou, no mínimo, que os gastos sejam previstos na execução da pesquisa científica.

Exemplos de títulos de acesso aberto estão na Public Library of Science ([2003?]), organização sem fins lucrativos e gerenciada por cientistas, com o intuito de abrir as portas do conhecimento científico, dando a qualquer indivíduo, de qualquer país, a chance de acesso ilimitado às informações em saúde recém-geradas. No momento, são cinco títulos no campo das ciências da vida: PLoS Biology; PLoS Medicine; PLoS 
Computational Biology; PLoS Genetics; e PLoS Pathogens, os quais mantêm as características mais relevantes das revistas científicas, quais sejam: revisão dos pares e padrões editoriais e de produção rigorosos, com a vantagem de disponibilizar o conteúdo on-line de imediato, sem custos e sem restrições de acesso.

Há, ainda, a BioMed Central, editora comercial, também na área biológica e da saúde, com mais de 100 títulos no sistema Open Access: os resultados de pesquisa estão de imediato disponíveis on-line sem cobrança de taxa, mas alguns títulos exigem assinatura institucional ou individual, no caso de acesso a outros tipos de textos, como revisões de literatura ou relatórios. Dentre as especialidades contempladas estão: biotecnologia, câncer, doenças cardiovasculares, farmacologia, patologia clínica, dermatologia e endocrinologia. $\mathrm{Na}$ América Latina, a Universidad Nacional Autónoma de México mantém o Sistema Regional de Información en Línea para Revistas Científicas de América Latina, el Caribe, España y Portugal. Além de prover informações adicionais sobre um conjunto selecionado de revistas por meio de catálogo e manter um índice para remissão a recursos eletrônicos, o Latindex produz diretório com mais de 12 mil títulos de revistas, incluindo as de acesso aberto (Targino, 2006).

Ainda na América Latina, a primeira iniciativa de acesso aberto ao conteúdo integral de periódicos científicos em várias áreas é o Projeto SciELO ou Scientific Electronic Library Online (http://www.scielo.br), resultante de proposta da Fundação de Amparo à Pesquisa do Estado de São Paulo (Fapesp) em parceria com o Centro Latino-Americano e do Caribe de Informação em Ciências da Saúde (Bireme). O propósito é desenvolver uma metodologia comum para preparação, armazenamento, disseminação e avaliação da produção científica em formato eletrônico. De início, o SciELO contemplava apenas títulos brasileiros. No momento, está sendo utilizado em outras nações, como Chile, Cuba e Espanha, dentre outras.

Por fim, podemos sintetizar as vantagens do acesso livre à informação: maior rapidez do fluxo informacional; maior visibilidade dos trabalhos publicados e do impacto dos resultados, com ampliação das possibilidades de maior número de citação; comunicação mais eficaz entre os sistemas e os repositórios, ou seja, maior interoperabilidade entre os arquivos; recuperação e compartilhamento mais eficientes das informações; e menor custo de divulgação.
Porém, o acesso livre à informação não se contrapõe, de forma simplista, à manutenção dos periódicos científicos impressos e assinados. É, sim, expressão de luta para que a divulgação dos resultados de pesquisas científicas, sobretudo as financiadas com recursos públicos, estejam disponíveis para qualquer interessado, sem custo, nos repositórios de acesso livre, haja vista as colocações anteriores, que reforçam a informação científica como instrumento essencial ao processo desenvolvimentista de qualquer nação. Assim sendo, o acesso livre à informação impõe-se como modalidade de publicação de artigos científicos que cresce, de forma veloz.

Ademais, o lbict tem investido no desenvolvimento de ferramentas, utilizando softwares e arquivos de código aberto. É o caso, por exemplo, da base de dados da Biblioteca Digital de Teses e Dissertações (BDTD) e do Sistema Eletrônico de Editoração de Revistas (Seer), soffware livre que favorece a edição de periódicos científicos eletrônicos, acrescentando-se que, até setembro de 2005, 55 títulos estavam sendo assim publicados. E uma prova incontestável da atenção da classe bibliotecária ao tema em questão é a constatação, conforme e-mail enviado pelo lbict a participantes deste Seminário, relacionando os textos que versam, direta, ou indiretamente, sobre o tema, e cujo total já chega a cinco.

\section{NOVAS ALTERNATIVAS}

\section{Creative Commons}

Além da expansão dos arquivos abertos, temos - Creative Commons (CC). Consiste em projeto sem fins lucrativos, vigente em vários países, incluindo o Brasil, que disponibiliza licenças flexíveis para obras intelectuais. Construído a partir da lei atual de direitos autorais, possibilita o compartilhamento de criações, incluindo músicas, filmes, imagens e, também, textos on-line (científicos ou não), devidamente identificados com licença CC. Tomando como referência a idéia dos direitos reservados, como se dá nos direitos autorais tradicionais, o CC adota a opção de "alguns direitos reservados".

Isto é, com a referida licença, o autor mantém os seus direitos autorais, mas, simultaneamente, possibilita a outros copiar e distribuir a sua obra, com a condição de que atribuam o devido crédito, 
obedecendo às condições previamente especificadas. Caso o autor disponibilize a sua produção, sem nenhuma restrição, deve optar pelo domínio público (Creative..., 2006). Conseqüentemente, o CC emerge como uma das formas de acesso e de uso da informação científica, de cunho democrático.

\section{Open Source Journalism (OSJ)}

E há mais. Em termos ideais, é atribuição de pesquisadores e comunidades científicas compartilhar os conhecimentos científicos com a sociedade, o que requer aproximação maior entre jornalistas e cientistas. Ciência e jornalismo não constituem esferas autônomas ou antagônicas. O cientista é identificado como produtor de conhecimento no sentido estrito do termo, enquanto o jornalista é o intermediário e o agente que facilita $\mathrm{o}$ acesso das camadas sociais à produção científica. Sem detalhar as barreiras que dificultam a interação entre as duas categorias, em termos concretos, trata-se da adoção dos pesquisadores (incluindo os cientistas da informação) da prática de repassarem ao grande público ou ao público-alvo os resultados das suas investigações, tanto em termos de instituições, como de pessoas.

Se a comunicação científica é básica àqueles que fazem ciência, a produção da ciência tem interesse eminentemente social, e assim sendo, deve estar ao alcance da população, cabendo ao cientista recorrer ao jornalismo científico, que também encontra, na Internet, condições propícias para a sua prática. E há experiências recentes nesse sentido. Estamos falando da experiência do Centro de Mídia Independente (CMI), site Indymedia, criado em 1999, em Seattle, nos EUA. É uma rede internacional de produtores de mídia, comportando cerca de 200 centros interligados, e espalhados em vários países, inclusive o Brasil, embora, a bem da verdade, a maioria esteja nos EUA. Impõese como alternativa ao jornalismo e ao webjornalismo de referência vigente na mídia convencional. O CMI Brasil (http://www. midiaindependente.org) constitui o "braço" desta rede no Brasil.

Tradicionalmente, o jornalista transforma o acontecimento (matéria-prima) em notícia (produto), com base nas condições de produção ao qual está submetido, dentro de relação tridimensional, que envolve três pólos: o evento, o jornalista, o cidadão. Para Ramonet (1999, p. 60), nesse caso, o evento era virado pelo avesso pelo jornalista que o verificava, o filtrava, o analisava, antes de transmiti-lo ao cidadão. Agora, este triângulo transformou-se num eixo que tem, de um lado, o evento, de outro, o cidadão. A função do jornalista desapareceu. A meio caminho não há mais um filtro ou um crivo, mas simplesmente um vidro transparente.

Tal transcrição nos remete ao contexto de webjornalismo, e, sobretudo, ao que se chama de open source journalism (OSJ). A atuação do jornalista, enquanto filtrador ou gatekeeper, está em processo de mutação, mutação esta, que atinge outros aspectos pertinentes às rotinas produtivas da notícia nos meios eletrônicos. Para Leal (2007), há crescente chance de utilizar a mídia para veicular novas informações, favorecendo o surgimento quase ilimitado de "jornalistas". Isto é, os novos processos inseridos na Internet dão margem a outro tipo de jornalismo, independente da mídia de referência, e sem intervenção do jornalista enquanto gatekeeper.

Tanto nas comunidades virtuais como no OSJ, surge a figura do ciber-cidadão ou leitor-produtor de informação. A conquista maior é a participação efetiva da comunidade. Percebemos nítida inversão de papéis: ora se produz informação, ora se checa e critica. Leal (2007, p. 63) acrescenta:

"[...] as competências são disseminadas e assumidas por todos, diferentemente [...] da mídia convencional ou do webjornalismo de referência, em que os papéis são previamente determinados e separados. De um lado, o emissor e produtor, que detém a informação e decide como tratá-la e divulgá-la. De outro, o receptor, que muito pouco interfere no processo".

O conceito assimilado pelo OSJ no CMI, qual seja, o princípio da democratização e do livre acesso à informação, vem da utilização do open source software. Em confronto com o mundo da Microsoff, da Netscape, da Sun Microsystems, o CMI disponibiliza meios de acesso ao conhecimento para a população em geral, favorecendo o processo participativo de construção da realidade. No entanto, o livre acesso e a possibilidade de voz para todos não são os traços únicos dos Centros de Mídia. Há a perspectiva de que informação (científica ou não) e cultura circulem livremente, sem assumir a natureza de mercadoria.

Logo, é uma medida, como as demais aqui arroladas, um tanto "revolucionária". Contraria o modelo vigente nas sociedades capitalistas, em que a 
informação, de qualquer natureza, possui caráter mercadológico prioritário, ou seja, a informação ou a sua disseminação é elitista e renega, na prática, o processo de democratização, ao refutar os conflitos e as disparidades existentes entre os diferentes estratos sociais.

Por conseguinte, quem publica no $\mathrm{CMI}$, abre mão, de forma integral ou parcial, dos direitos de autoria, por meio de uma licença, a copyleft, que permite a reprodução não comercial das matérias, vetando, porém, o uso comercial, a não ser mediante consulta ao autor. Neste caso, quem discordar das diretrizes do $\mathrm{CMI}$ pode solicitar a inclusão de nota junto à licença copyleft, esclarecendo que permite a reprodução para fins não comerciais, desde que citados autor e fonte. Tal como ocorre com o CC, o termo copyleft opõe-se ao sistema copyright, com a diferença vital que a sua natureza é jornalística.

No caso do CMI Brasil, a política editorial está sujeita a mudanças. Há espaço para a administração do site, que pode remanejar matérias para outras áreas do portal. Por exemplo, matérias que contrariam a política básica do CMI, ou por sua temática polêmica (racismo, sexo etc.), ou por seu teor discriminatório, ou por conteúdo ofensivo, ou por sua natureza de propaganda comercial e/ou política, ou por já terem sido antes veiculadas, mesmo continuando no site, são postas numa seção denominada de "lixo aberto" ou "artigos escondidos".

Segundo dados do Centro... (2006), o coletivo editorial e os voluntários administradores preocupamse tanto com o conteúdo do que é veiculado como com a integridade dos textos dos colaboradores: quando muito, se for o caso, são feitas correções editoriais para tornar as matérias mais legíveis ou adequadas aos padrões estabelecidos. Dentre outras recomendações constantes da linha editorial, estão os esclarecimentos sobre a não responsabilidade em relação aos conteúdos, a natureza do CMl como site de notícias, o que significa dizer que comporta informações científicas veiculadas por meio do jornalismo científico. Isto é, trata-se de nova alternativa de acesso e de uso da informação científica.

○ CMI, por permitir livre acesso à publicação, favorece a visibilidade dos conteúdos produzidos, e, também, mantém processo de hierarquização das notícias, de modo a preservar a credibilidade do veículo: há matérias publicadas ou reorganizadas pelo coletivo editorial, que merecem destaque, além de textos de autoria dos usuários mais freqüentes e em consonância com os ditames editoriais preestabelecidos, em contraposição ao material do "lixo aberto". Sem dúvida, isto se aproxima da prática noticiosa mais tradicional, vez que é inevitável certa análise e conseqüente categorização dos conteúdos. De qualquer forma, é evidente que o OSJ é uma forma de democratização do acesso e do uso da informação.

\section{FINALIZANDO}

Por fim, o exposto mostra as infinitas possibilidades das redes eletrônicas de informação e de comunicação, com ênfase para a Internet, sobretudo, no momento em que permite a cada um suprir as suas demandas no que concerne à informação científica, em tempo ágil, com maior acuidade, vislumbrando o indivíduo em suas potencialidades e limitações, e não mais como elemento "cinzento" de uma massa amorfa e disforme.

No entanto, tal reconhecimento não comporta enaltecimento irrestrito. Ao contrário. Reconhecemos a Internet como processo de transformação profunda da realidade, mas também, vislumbramos os seus efeitos colaterais, no sentido de que provoca uma série de conseqüências, tais como: possibilidade maior de informações inconsistentes; dificuldade crescente na triagem das informações existentes; complexidade de armazenamento e do controle bibliográfico; banalização da autoria; desrespeito à propriedade intelectual; uso não-ético do conteúdo disponibilizado; invasão da privacidade; e ênfase a relações impessoais.

A questão, portanto, é reconhecer os seus méritos e lidar criativamente com os riscos que provoca. É a perspectiva de rasgar o seu véu de magia e de purismo, vez que nenhum processo social desencadeado pelas inovações tecnológicas pode ser analisado de forma isolada. A cultura está na fronteira do material e do simbólico, interagindo com o mundo da produção e com as representações imaginárias. Não há soluções únicas e permanentes para sociedades múltiplas e voláteis. É utopia pensar num suporte informacional acessível à humanidade como um todo, diante das singularidades dos indivíduos, dos grupos sociais, dos povos e das nações. Importa sim, a adoção de uma visão humanista e realista, que considera liberdade como respeito, aceitação e convivência com o diferente, nas mais diferentes instâncias. 
E, de fato, quando da explosão da Internet, se proclamava o fim do papel - "num futuro próximo, não haverá mais livrarias, senão as virtuais", dizia-se. Não estamos vendo isto acontecer. Um dos nossos primeiros textos, divulgado no Jornal do Commercio (Recife), em 1968, face ao avanço do microfilme, discutia a questão - a morte do livro: realidade ou ficção? A discussão persiste. Mas o livro, usado, aqui, como sinônimo do suporte impresso, sobreviverá por longo tempo, ao lado da produção científica eletrônica. Afinal, o clímax de cada inovação tecnológica tem o seu próprio espaço, o seu próprio tempo, o seu próprio público, sem riscos reais de que o mundo se torne uma aldeia global. Em anos e anos de informação multifacetada, não há registro de casos de extinção de veículos de comunicação face ao surgimento de outros. Ocorrem, sim, mutações, adaptações e avanços.

Logo, o periódico científico impresso vai persistir. O elenco das alternativas ora apresentado, apenas estimula a criatividade para que editores e instituições mantenedoras de periódicos (mesmo eletrônicos) encontrem meios financeiros de sustentáculo para os "seus" títulos, indo além do Conselho Nacional de Desenvolvimento Científico e Tecnológico e das fundações estaduais de amparo à pesquisa. Um bom exemplo é o Portal de Periódicos mantido pela Capes. Há, também, a chance de envolvimento das associações de classe e, sobretudo, das sociedades científicas, a exemplo da pool de sociedades científicas que se reúne para editar o bem-sucedido Brazilian Journal of Medical and Biological Research, em que o compartilhamento é elemento essencial. Há, ainda, empresas que financiam títulos, o que lhes favorece desconto de impostos. Consiste em parceria entre público e privado, que conquista espaço mais e mais, além da oportunidade de destinar páginas para publicidade de empresas,

\section{REFERÊNCIAS}

BARRETO, A. Mudança estrutural no fluxo do conhecimento: a comunicação eletrônica. Ciência da Informação, v.27, n.2, 1998. Disponível em: <http://www.ibict.br/cienciada informacao >. Acesso em: 25 abr. 2005.

BRASIL. Ministério da Ciência e Tecnologia (MCT). 2006 a. Estatísticas e indicadores. Disponível em: <http://www.mct. gov.br>. Acesso em: 22 set. 2006.

BRASIL. Ministério da Ciência e Tecnologia (MCT). 2006b. Webmasters dos indicadores de ciência e tecnologia. [mensagem pessoal]. Mensagem recebida por<gracatargino@hotmail. com>. em 22 set. 2006. desde que estas mantenham alguma relação com a temática central do periódico, para não comprometer a sua credibilidade, como Dias e Garcia (2006) alertam.

Em suma, reiteramos que a Internet faz jorrar publicações eletrônicas, mas estas não são, necessariamente, contribuições científicas. $O$ caminho pode estar em múltiplas alternativas, com destaque para o movimento mundial pelo acesso livre à informação, por intermédio da expansão dos repositórios de acesso livre e/ou dos softwares de código aberto. É a confirmação das palavras quando ainda Barreto (1998), afirmou:

A comunicação eletrônica veio definitivamente libertar o texto e a informação de uma ideologia envelhecida e autoritária dos gestores da recuperação da informação, defensores de uma pretensa qualidade ameaçada, os fatais intermediários e porta-vozes que vêem seus poderes ameaçados cada vez mais pela facilidade da convivência direta entre os geradores e consumidores da informação.

É a esperança de uma sociedade, onde a miséria, que ora convive com a sofisticação tecnológica, possa ser substituída por oportunidades iguais e justas de melhor qualidade de vida. Se assim for, é possível que, em resposta a Castro (1986), quando questiona: "O que é melhor, ser peão de uma ciência sofisticada ou rei de um arremedo tupiniquim de ciência?", possamos ter a certeza de que o cientista brasileiro pode se orgulhar de ser rei, não de um arremedo tupiniquim da ciência, mas de uma ciência verdadeiramente universal. Isto significa a esperança de não perdermos - "bonde da modernidade", ao tempo que significa não perdermos de vista o lado humano intrínseco à ciência, como algo a nosso serviço, ou seja, a serviço da humanidade.
CASTRO, C.M. Há produção científica no Brasil? In: SCHWARTZMAN, S., CASTRO, C.M. (Org.). Pesquisa universitária em questão. Campinas: UNICAMP, 1986. p. 190-224.

CENTRO DE MÍDIA INDEPENDENTE BRASIL (CMI Brasil). [CMI]. Disponível em: <http:// www.midiaindependente.org > . Acesso em: 22 out. 2006.

CREATIVE COMMONS. Disponível em: <http://www.creative commons.org.br>. Acesso em: 20 out. 2006.

DIAS, G.A.; GARCIA, J.C.R. Periódicos científicos impressos e eletrônicos: financiamento, recursos tecnológicos e custos. São Paulo, 2006. 19f. (Digitado). 
INSTITUTO BRASILEIRO DE INFORMAÇÃO EM CIÊNCIA E TECNOLOGIA (IBICT). Ibict lança manifesto pelo acesso livre à informação científica. 14 set. 2005. Disponível em: <http: // www.ibict.br/openaccess > . Acesso em: 19 out. 2006.

INTERNET NO BRASIL. ComCiência, 10 mar. 2001. Disponível em: < http://unw.mp.br/ noticias/imprensa > . Acesso em: 19 out. 2006

LEAL, A.R.B.R. Open source journalism e cidadania: Centro de Mídia Independente Brasil. In: LEAL, A.R.B.R. Jornalismo, cultura e poder. Teresina, Edufpi, 2007.

MÁRDERO ARELLANO, M.Á.; FERREIRA, S.M.S.P.; CAREGNATO, S.E. Editoração eletrônica de revistas científicas com suporte do Protocolo OAI. In: TARGINO. M.G. (Org.). Preparação de revistas científicas: teoria e prática. São Paulo: Reichmann \& Autores Ed., 2005.
MASON, R. O. What is an information professional? Journal of Education for Library and Information Science, Arlington, v.31, n.2, p.122-138, 1990.

PUBLIC LIBRARY OF SCIENCE (PLoS). About PLoS. [2003?]. Disponível em: <http://www.plos.org>. Acesso em: 29 set. 2006.

RAMONET, I. A tirania da comunicação. Petrópolis: Vozes, 1999.

TARGINO, M.G. Olhares e fragmentos: cotidiano da biblioteconomia e ciência da informação. Teresina: UFPI, 2006. 266p.

THE UNITED KINGDOM PARLIAMENT. Science and technology tenth report. London: House of Commons, 2004. Disponível em: $<$ http://www. publications. parliament.uk.htm>. Acesso em: 22 set. 2006.
105

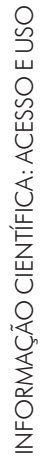


